\title{
Prevelance of total coliforms, faecal coliforms and $E$. coli in Rawalpindi vegetable markets
}

\author{
Sadia Alam ${ }^{*}$, Samina Khalil ${ }^{2}$, Najma Ayub $^{3}$, Abida Bibi $^{3}$, Beena Saeed ${ }^{4}$, Salma Khalid ${ }^{5}$, \\ Sumaira Siddiq ${ }^{6}$ \\ ${ }^{1}$ Department of Microbiology, University of Haripur, Haripur, Pakistan; *Corresponding Author: drsadia.alam2012@gmail.com \\ ${ }^{2}$ IFood Quality Programme, National Agriculture Research Centre, Islamabad, Pakistan \\ ${ }^{3}$ Department of Microbiology, Quaid-i-Azam University, Islamabad, Pakistan \\ ${ }^{4}$ Department of Agriculture, Abdul Wali Khan University, Mardan, Pakistan \\ ${ }^{5}$ Department of Environmental Sciences, Abdul Wali Khan University, Mardan, Pakistan \\ ${ }^{6}$ Department of Biotechnology, Abdul Wali Khan University, Mardan, Pakistan \\ Received 2 June 2013; revised 2 July 2013; accepted 9 July 2013 \\ Copyright (C) 2013 Sadia Alam et al. This is an open access article distributed under the Creative Commons Attribution License, \\ which permits unrestricted use, distribution, and reproduction in any medium, provided the original work is properly cited. In accor- \\ dance of the Creative Commons Attribution License all Copyrights (C) 2013 are reserved for SCIRP and the owner of the intellectual \\ property Sadia Alam et al. All Copyright (C) 2013 are guarded by law and by SCIRP as a guardian.
}

\begin{abstract}
Nutritional value of vegetables and high prices of meat and meat originated food compel common people to consume plant originated food particularly salad vegetables. Microbial population of vegetable surfaces contains a large number of pathogenic bacteria including members of Enterobactereace like Escherichia coli (E. coli). A survey was conducted in three major markets of Rawalpindi, Pakistan. Tomato, lettuce, cabbage and cucumber samples were collected from three shops of each market. Each vegetable was analysed as unwashed and washed for total coliforms, faecal coliforms and $E$. coli by FAO (Food Quality Manual). About two hundred and fifty $E$. coli isolates were preserved, serotyped for presence of 0157 serotype. Total coliforms, faecal coliforms and $E$. coli count exceeded the permissible limits in most samples. The highest Total coliforms were associated with cabbage (3.78 $\left.\log _{10} \mathrm{cfu} / \mathrm{g}\right)$. Cucumber was the least contaminated by Total coliforms $\left(2.15 \log _{10} \mathrm{cfu} / \mathrm{g}\right)$. $E$. coli was detected in tomato, lettuce, cucumber and cabbage. Washed samples showed reduced bacterial population. Seventy six isolates of $E$. coli were biochemically characterized and serotyped for 0157 antigen. A majority of strains could not be identified by serotyping. These findings conclude with high potentially pathogenic microbial load on salad vegetables and urge for preventive action on priority basis.
\end{abstract}

Keywords: Escherichia coli; Total Coliforms; Fecal Coliforms; Vegetables; Serotyping; Microbial Population

\section{INTRODUCTION}

Foodborne illness has recently gained much attention worldwide due to its deleterious effects on human health and consequentially on national economy. Worldwide increased consumption of fresh vegetables in the form of raw and minimally processed salads has resulted in increase in foodborne outbreaks which sometimes may be fatal [1]. Food trade among various countries may bring in additional food safety challenges by allowing extensive spread of unhygienic food, and predominantly produce [2].

Foodborne outbreaks are witnessed by people of developed countries like the United States, Japan and Germany $[3,4,5]$. Coliform bacteria, particularly E. coli, are an index of water and food sanitation. Some of the strains are pathogenic like E. coli O157:H7 and are able to produce serious illness in humans including diarrhoea, vomiting, severe abdominal pain, hemorrhagic colitis (HC), and the acute hemolytic uremic syndrome (HUS) $[6,7]$.

Foodborne illnesses seldom come into notice in developing countries like Pakistan. The proposed study is thought to assess the risk related to consumption of contaminated salad vegetables by detecting total coliforms, faecal coliforms and E. coli associated with salad vegetables sold at retail shops of Rawalpindi. Data generation for health policy makers and to have a view of difference between contamination level of unwashed and washed 
vegetables were also the research objectives.

\section{MATERIAL AND METHODS}

Three markets of Rawalpindi were randomly selected i.e. Khannapul vegetable market, Chungi 22 vegetable market and Rajabazar vegetable market. Four salad vegetables (1 kg each) i.e. tomato, lettuce, cucumber and cabbage were sampled from three random markets of the city.

\subsection{Sample Analysis}

Each sample was coded and analysed for total coliforms, faecal coliforms and E. coli as (a) unwashed (b) washed. Sample was prepared and serially diluted in Butterfield phosphate buffer according to method described in FAO Manual (1992) [8].

Diluted Butterfield phosphate buffer and all media required were autoclaved at $121^{\circ} \mathrm{C}$ and 15 pounds/sq. inch pressure for 15 - 20 minutes in Harvey Sterile Max autoclave (USA).

\subsection{Presumptive Test for Total Coliforms and Faecal Coliforms}

One ml blended sample was put in Pyrex screw cap test tubes containing $9 \mathrm{ml}$ sterile Lauryl sulphate Tryptose (Oxoid) broth and inverted Durhum tubes and incubated at $35^{\circ} \mathrm{C}$ for $24-48 \mathrm{hrs}$ in Binder incubator. Production of gas in inverted Durhum tubes was the presumptive test for coliforms presence in the sample.

\subsection{Confirmatory Tests for Total Coliforms}

Positive cultures in LST tubes were transferred to sterile BGLB (Oxoid) tubes and incubated at $35^{\circ} \mathrm{C}$ for 24 $48 \mathrm{hrs}$ in incubator. Gas production in inverted Durham tubes confirmed the presence of coliforms in sample. Their number was assessed by counting confirmed positive test tubes of consecutive three dilutions using MPN technique.

\subsection{Confirmatory Test for Faecal Coliforms}

Positive LST culture was transferred to sterile $10 \mathrm{ml}$ EC medium and incubated for $48 \pm$ hours at $45.5^{\circ} \mathrm{C}$ in GFL 1086 waterbath (Germany). MPN of faecal coliforms was calculated from positive EC tubes for consecutive three dilutions.

\subsection{Biochemical Test for E. coli}

E.coli isolates were confirmed by performing tests for indole production, methyl red reactive compound tests, Voges Proskauer reactive compound tests, and citrate utilization. IMViC pattern of ++-- and -+-- was interpreted as Biotype I and II E. coli strains, respectfully. Some strains showing atypical characteristics were Gram stained.

All isolated strains of $E$. coli were tested for catalase production as described by Collins and Lyne (1980) [9].

\subsection{Serotyping 0157}

In order to serotype the Enterohemorrhagic strain of E.coli, among the isolated strains, O157 Oxoid (DR120M) Dryspot Latex detection kit was used.

All isolates from fresh produce were coded as VB (Vegetable Bacteria) and given a number. All E. coli isolates from salad vegetables were preserved for short term on Nutrient agar (Sigma) slants and long term by freezedrying in 10\% skim milk (Difco).

\subsection{Statistical Analysis}

All experiments were performed in triplicate. The means, standard deviation and standard error of all experiments was determined. Graphs preparation and standard error calculation was performed in Excel 2010. Bifactoral Analysis of Variance (ANOVA) was applied to know the significance of washed and unwashed vegetables of different markets. Pairwise T test was applied (Statistix 8.1) to assess the difference between each vegetable in unwashed and washed conditions. Total Coliforms, Faecal Coliforms, E. coli values were also converted to $\log 10$ before graph preparation.

\section{RESULTS AND DISCUSSION}

A total of 36 samples were collected from their respective shops and markets and coded after transporting to the laboratory.

\subsection{Samples Collection}

Table 1 indicates details of the samples collected and the code given in the Food Microbiology Laboratory of Grain Quality Testing Laboratory (GQTL), National Agriculture. Research Centre, Islamabad.

\subsection{Sample Analysis: pH Studies}

Lowest $\mathrm{pH}$ values were recorded for tomatoes while cabbage and lettuce blended samples showed highest $\mathrm{pH}$ values in overall survey Figure 1. Rawalpindi city contained vegetables of $\mathrm{pH} 4.75$ (FMS105abc, tomato, Khannapul) to 6.23 (FMS217abc, lettuce, Rajabazar). This result is similar to the findings of Dobricevic et al. (2005) [10] and Chutichudet et al. (2011) [11]. pH values of cabbage and lettuce were found to be close to one another while that of cucumber and tomato varied differently from other vegetables tested. Cabbage analysed for $\mathrm{pH}$ values indicated that it ranged from 5.6 - 5.94 while cucumber 
Table 1. Details of samples collected from different markets of Rawalpindi.

\begin{tabular}{cccc}
\hline S.NO & Sample Code & Vegetable Type & Market \\
\hline 1. & FMS105abc & Tomato & Khanapul \\
2. & FMS106abc & Cucumber & Khanapul \\
3. & FMS107abc & Cabbage & Aabpara \\
4. & FMS202abc & Cucumber & Rajabazar \\
5. & FMS209abc & Tomato & Rajabazar \\
6. & FMS216abc & Cabbage & Rajabazar \\
7. & FMS217abc & Lettuce & Rajabazar \\
8. & FMS258abc & Tomato & Chungi22 \\
9. & FMS265abc & Cabbage & Chungi22 \\
10. & FMS277abc & Cucumber & Chungi22 \\
11. & FMS282abc & Lettuce & Khannapul \\
12. & FMS283abc & Lettuce & Chungi22 \\
\hline
\end{tabular}

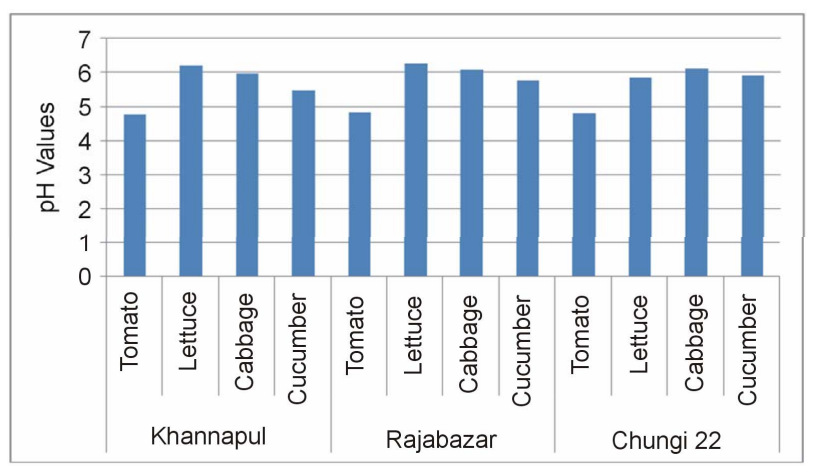

Figure 1. $\mathrm{pH}$ of blended vegetable samples isolated from different markets of Rawalpindi.

ranged from 5.09 - 6.41. This result could not be compared with other results as $\mathrm{pH}$ values related to blended cabbage sample in sterile distilled water was lacking in literature. Average $\mathrm{pH}$ of cucumber was found to be 5.7 by Barathi et al. (2001) [12]. It was noted that vegetables with high $\mathrm{pH}$ values harboured more microorganisms as compared to vegetables with low $\mathrm{pH}$ values. This trend was also found by Weissinger et al. (2000) [13].

\subsection{Total Coliforms}

Rawalpindi markets revealed results that cabbage from Khannapul was highly contaminated followed by lettuce, cucumber and least count was found on tomatoes Figure 2. Data for Total coliforms showed non significant $(\mathrm{p}<$ 0.05 ) difference between three markets of Rawalpindi. It also shows Rajabazar vegetable market analysis for salad vegetables contamination with total coliforms. Cucumber was found with highest number coliforms followed by tomato and cabbage while cucumbers were least contaminated. Chungi No. 22 vegetable market exhibited cabbage as most contaminated salad vegetable while cucum- ber was least contaminated. Tomato and lettuce contained almost equal number of coliforms. Washing has significantly $(\mathrm{p}<0.05)$ reduced the number of coliforms on cabbage and lettuce but non-significance difference was noted for cucumber and tomato in chungi 22 vegetable market. This result resembles to the outcome of investigation conducted by Manios et al. (2006) with minor difference in total coliform counts [14]. Al-Lahham et al. (2003) also found tomato fruit contaminated with total coliforms [15]. These types of figures were also obtained by Johnston et al. (2006) and Machado et al. (2006) [16, 17]. Analysis of variance revealed that washed samples showed significantly $(p<0.05)$ decreased number of total coliforms in all vegetables. This result is similar to the findings of Yasmeen et al. (2008) and Ibrahim and JudeOjei $(2009)[18,19]$.

\subsection{Faecal Coliforms}

Results of faecal coliforms exhibited presence of faecal contamination in all samples collected from all vegetable markets of Rawalpindi and the results revealed that lettuce contained maximum number of faecal coliforms. Machado et al. (2006) found faecal count more than $10^{2}$ $\mathrm{cfu} / \mathrm{g}$ on lettuce which is less than the count obtained in present study faecal load (maximum values $10^{6}$ ) [17]. Stine et al. (2005) also concluded results indicating microbial load on fresh vegetables that resembled current findings [20]. Cabbage was associated with least number of faecal population Figure 3. This variation may be due to involvement of some additional factors like pesticides residues. Usually cabbages and radish are heavily sprayed to control vegetable pests [21]. Washed samples showed significantly $(p<0.05)$ lowered faecal contamination as compared to unwashed cucumber and cabbage. Rajabazar vegetable market were found with all samples contaminated with faecal coliforms. Among them lettuce contained highest faecal population while cabbage and tomato showed lower counts. Cabbage and lettuce vegetable samples of Chungi 22 vegetable market contained maximum number of faecal coliforms while cucumber and tomatoes showed lower results for faecal contamination. Pairwise $T$ test showed that each washed vegetable harbor significantly $(\mathrm{p}<0.05)$ less count than unwashed. Bifactoral ANOVA revealed non significant difference ( $\mathrm{p}$ $<0.05$ ) between different markets of Rawalpindi for faecal count. This finding shows similarity with $\mathrm{Xu}$ and Warriner (2005) and Jensen et al. (2010) [22,23].

Washing with sterile distilled water significantly $(\mathrm{p}<$ 0.05 ) reduced faecal contamination in all samples tested except cucumber. This result may be due to the presence of faecal coliforms in internal parts of cucumber fruit Figure 2 . These faecal coliforms may have entered through variable sources like faeces, contaminated irrigation water, animal wastes used as fertilizer, grazing animals, 


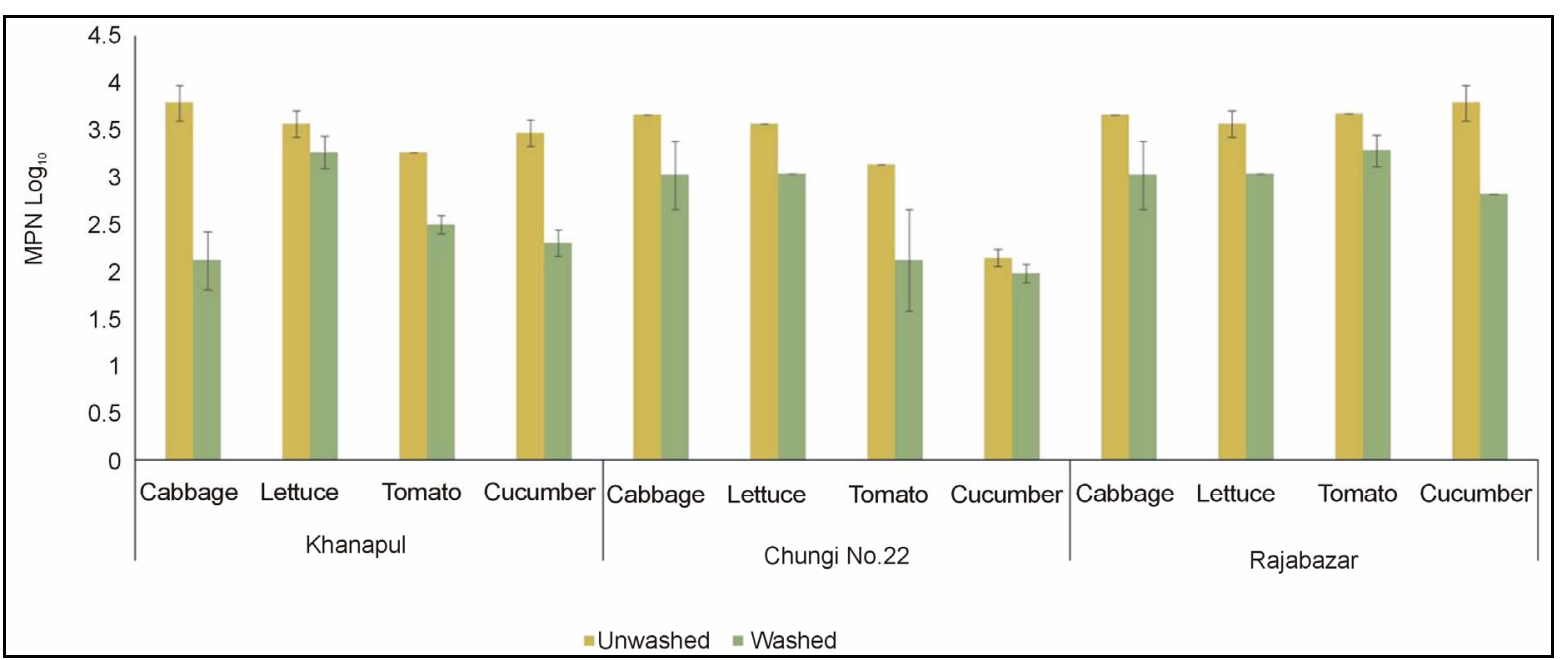

Figure 2. Total coliforms of unwashed and washed $\left(\log _{10} \mathrm{MPN} \pm \mathrm{S}\right.$.E) salad vegetables of three vegetable markets of Rawalpindi.

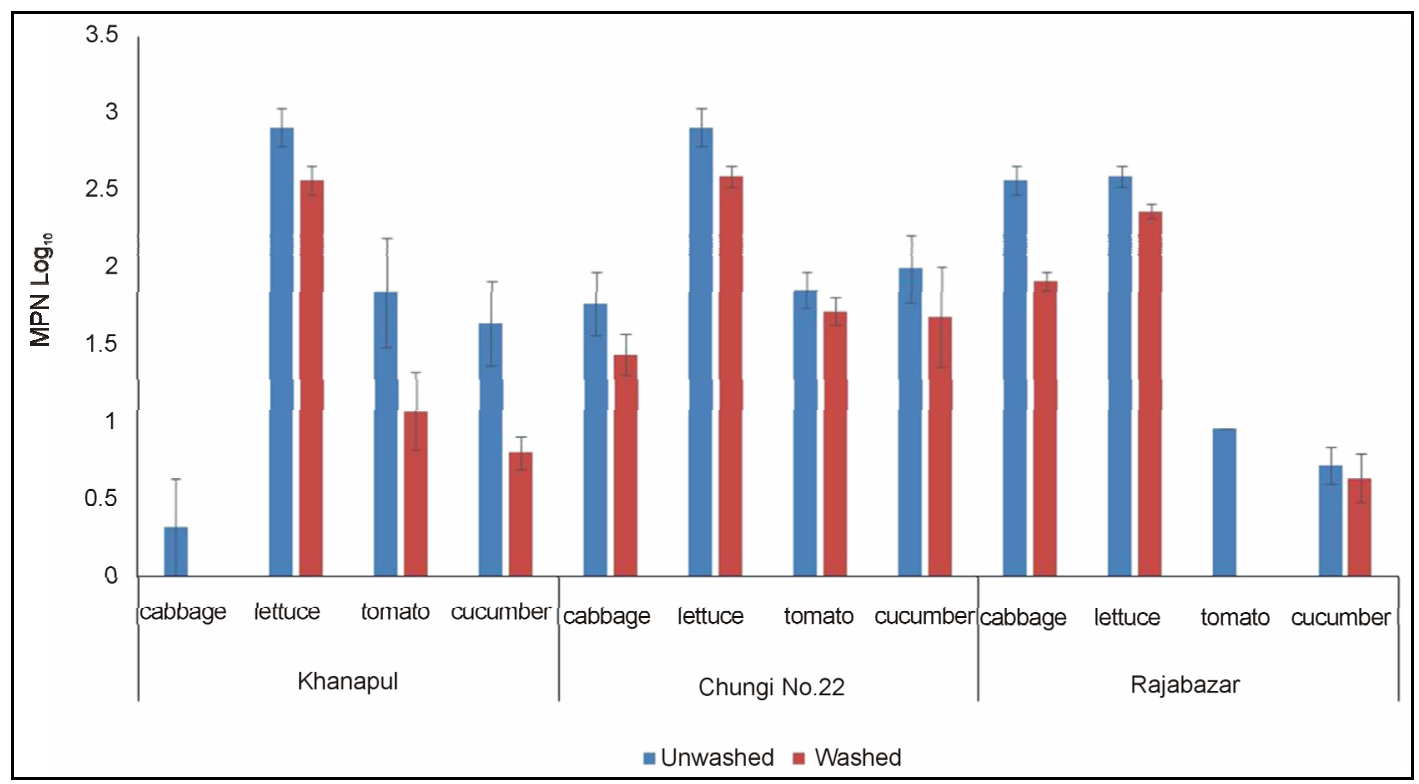

Figure 3. Faecal coliforms $\left(\log _{10} \mathrm{MPN} \pm\right.$ S.E) of unwashed and washed salad vegetables of Rawalpindi vegetable markets.

birds faecal droppings and human contact. The high count may also be result of contamination during transportation from fields to mandis and from mandis to retail outlets.

Heinonen-Tanski et al. (2007) found no enteric pathogens present on cucumbers samples. This is contradictory result to present may be because of human urine application to the soils where cucumber was grown by researchers [24].

\subsection{Escherichia coli}

Rawalpindi markets analysed for E. coli count showed that Khannapul vegetable market contained maximum $E$. coli count for lettuce and cabbage contained significantly $(p<0.5)$ lowest counts among all vegetables tested Fig- ure 4. Rajabazar vegetable market harboured lettuce being more contaminated than other vegetables while cabbage was observed with lower counts. Chungi 22 vegetable market cabbage was thickly contaminated with $E$. coli while cucumbers contained lower count. Same results were obtained by Mukherjee et al. (2004) and Soloman et al. (2003) [25,26]. Simeos et al. (2001) reported presence of E.coli in all samples of selected commodities [27]. Present results show a contradiction with the findings of Valentin-Bon et al. (2008) for presence of E. coli on lettuce [28]. The variation may have developed because of different ecological and sanitary condition of two countries. Washing significantly $(\mathrm{p}<0.05)$ reduced $E$. coli population of three markets of Rawalpindi studied. 


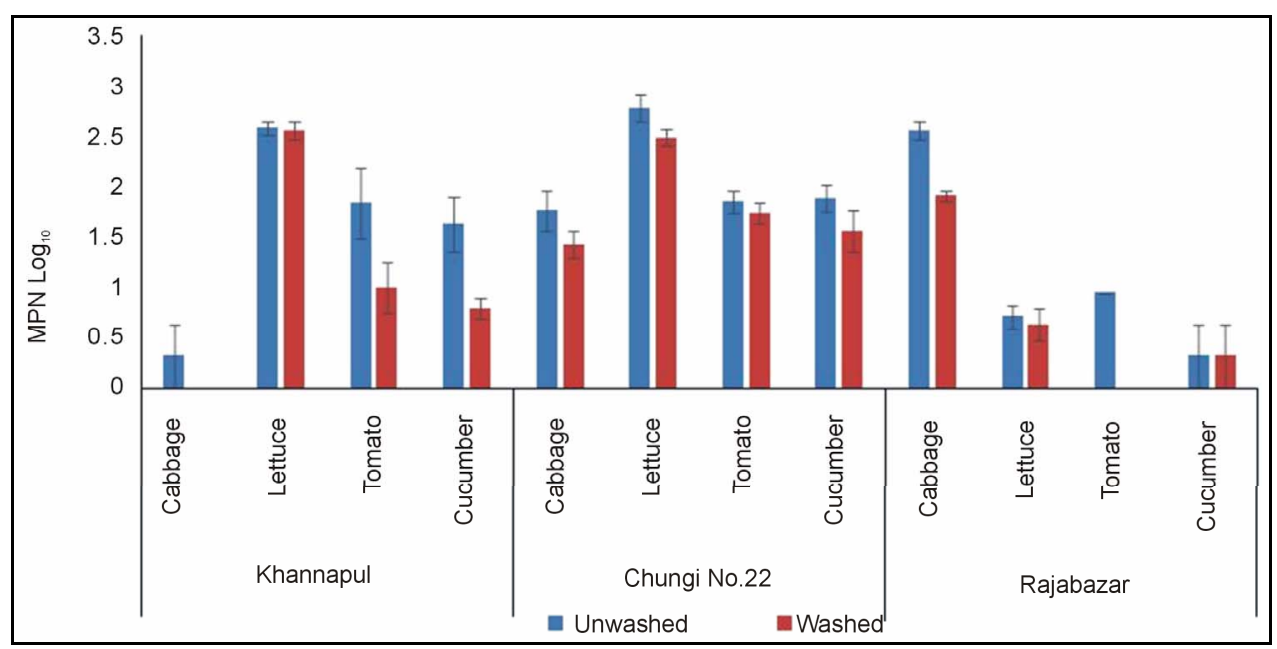

Figure 4. E. coli of unwashed and washed salad vegetables of three vegetable markets of rawalpindi.

Two factor analysis of variance for $E$. coli showed non significant $(p<0.05)$ difference between three markets of Rawalpindi.

It was also found that $E$. coli was more associated with lettuce. This association may be due the fact that leafy greens provide more surface area for contamination. $E$. coli count in tomato and cucumber was lower than the values of $E$. coli contamination detected by Bharathi et al. (2001) [12]. It is probable that E. coli attaches itself to the cut bruised area of vegetables more rapidly as compared to other pathogens.

Faecal coliforms number in most of samples was equal to the count of $E$. coli but in some cases faecal count was higher than E. coli count and is similar to the previous research work [28].

\subsection{Biochemical Tests of E. coli}

Khannapul vegetable market showed $18 \mathrm{E}$. coli isolates belonged to E. coli Biotype II while 7 were Biotype I. One E. coli strain (91VB) showed atypical characteristics and was confirmed as E. coli isolate after Gram staining and microscopy. Twenty eight $E$. coli isolates were obtained from Rajabazar of Rawalpindi. Nineteen $E$. coli isolates were Biotype I and 7 biotype II. Among 23 isolates of E. coli 19 were Biotype I, three were biotype II and one (161VB) showed atypical characteristics. All isolates produced catalase. Figure 5 shows catalase production by $E$. coli $157 \mathrm{VB}$ isolate of Chungi 22 vegtable market.

Indole production was noted in most of the isolates of each market. All E. coli strains were gas producing. These results are similar to the characteristics exhibited by strains by other researchers [29]. The difference may be result of $E$. coli isolates from different origin or genetic descendent from Shigella. Shigella cannot produce indole and E. coli isolates might possessed multivariant genetic origin [30]. Chungi 22 market indicated high

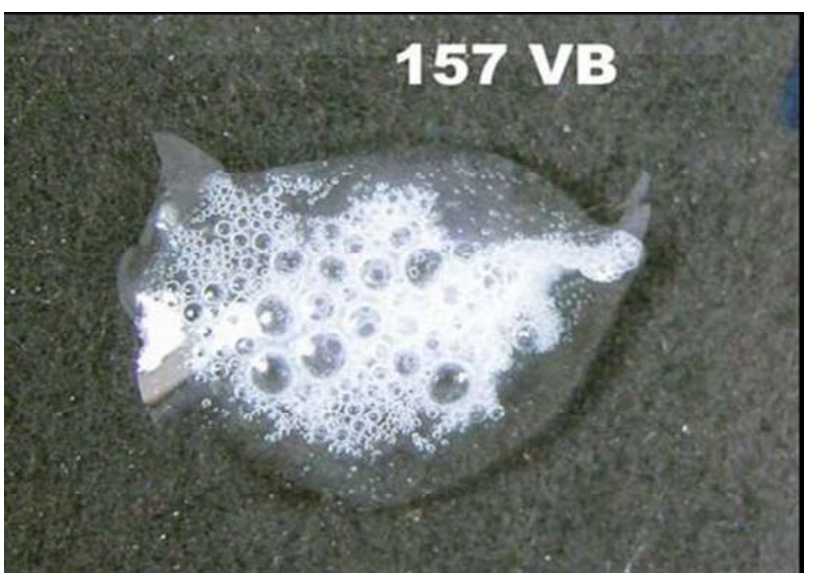

Figure 5. Catalase production by E. coli isolate $157 \mathrm{VB}$.

percentage of E. coli Biotype I (82.\%) as compared Biotype II $(13.04 \%)$ while $73 \%$ E. coli isolates obtained from Khannapul vegetable market were of Biotype II (Figure 6).

\subsection{Serotyping}

Serotyping results showed that 4 strains belonged to $E$. coli O157 (89VB, 92VB, 101VB and 112VB). Positive agglutination was noted for $\mathrm{O} 157$ serogroup while negative agglutination indicated presence of non O157. Stephen et al. (2008) did not isolate any O157:H7 strain [31]. This contradiction may be due to difference of sampling area and source of bacteria on salad vegetables.

\section{CONCLUSION}

It was concluded on the basis of present research findings that E. coli is highly prevalent in local vegetable markets of Rawalpindi, Pakistan. There was lack of proper sanitary conditions in retail outlets. A proper check and balance system was needed. Washing reduced the 


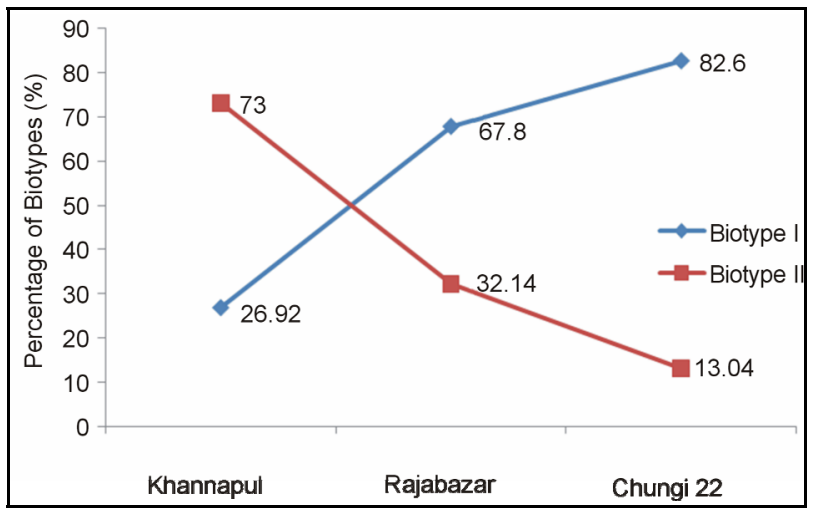

Figure 6. Percentage of biotypes of E. coli in three different vegetable markets of Rawalpindi.

microbial load on vegetables. The conclusions drawn from the results propel recommendations that a comprehensive sampling plans should be made, a regular survey of vegetable markets should be conducted after every three months and the faecal coliforms sources should be removed on priority. Cross contamination should be avoided by food handlers, distributors and field workers. Awareness must be created among public and political elites.

\section{ACKNOWLEDGMENT}

Authors particularly acknowledge Higher Education Commission (HEC), Pakistan, for funding the research project.

\section{REFERENCES}

[1] Little, C.L. and Gillespie, I.A. (2008) Prepared salads and public health. Journal of Applied Microbiology, 105, 17291743.

[2] Johnston, L.M., Jaykus, L.A., Moll, D., Anciso, J., Mora, B. and Moe, C.L. (2006) A field study of the microbiological quality of fresh produce of domestic and Mexican origin. International Journal of Food Microbiology, 112, 83-95.

http://dx.doi.org/10.1016/j.ijfoodmicro.2006.05.002

[3] CDC (Centers for Disease Control and Prevention, US) (2006) Update on multi-state outbreak of E. coli O157:H7 infections from fresh spinach.

http://www.cdc.gov/ecoli/2006/september/updates/10060 $\underline{6 . h t m}$

[4] Dempsey, J. and Neuman, W. (2011) The New York Times.

[5] http://www.foodsafetynews.com/2011/06/sprouts-suspect ed-in-germany-e-coli-outbreak/

[6] Verweyen, H.M., Karch, H., Brandis, M. and Zimmerhackl, L.B. (2000) Enterohemorrhagic Escherichia coli infections: Following transmission routes. Pediatric Nephrology, 14, 73-83. http://dx.doi.org/10.1007/s004670050018

[7] Karch, H., Tarr, P.I. and Bielaszewska, M. (2005) Enterohaemorrhagic Escherichia coli in human medicine. In- ternational Journal of Medical Microbiology, 295, 405418. http://dx.doi.org/10.1016/j.ijmm.2005.06.009

[8] FAO (1992) Manual of quality control: Microbial analysis IV, FAO, Rome.

[9] Collins, C.H. and Lyne, P.M. (1980) Microbiological methods. Butterworths, London, 4, 215-217.

[10] Dobricevic, N., Voća, S., Borošić, J. and Novak, B. (2005) Effects of substrate on tomato quality. International Symposium on Growing Media ISHS Acta Horticulturae, 779.

[11] Chutichudet, B., Chutichudet, P. and Kaewsit, S. (2011) Influence of developmental stage on activities on polyphenol oxidase, internal characteristics and colour of lettuce cv grand raphids. American Journal of Food Technology, 6, 215-225. http://dx.doi.org/10.3923/ajft.2011.215.225

[12] Barathi, S., Ramesh, M.N. and Varadaraj, M.C. (2001) Predicting the behavioral pattern of Escherichia coli in minimally processed vegetable. Food Control, 12, 275-284. http://dx.doi.org/10.1016/S0956-7135(01)00008-1

[13] Weissinger, W.R., Chantarapanont, W. and Beuchat, L.R. (2000) Survival and growth of Salmonella baildon in shredded lettuce and diced tomatoes, and effectiveness of chlorinated water as a sanitizer. International Journal of Food Microbiology, 62, 123-131.

http://dx.doi.org/10.1016/S0168-1605(00)00415-3

[14] Manios, T., Papagrigoriou, I., Daskalakis, G., Sabathianakis, I., Terzakis, S., Maniadakis, K. and Markakis, G. (2006) Treated and disinfected wastewater, irrigation of tomato and cucumber plants, under greenhouse conditions, regarding, growth and safety considerations. Journal of Water Environment Research, 78, 1.

[15] Al-Lahham, O., El Assi, N.M. and Fayyad, M. (2003) Impact of treated wastewater irrigation on quality attributes and contamination of tomato fruit 2003. Agricultural Water Management, 61, 51-62.

http://dx.doi.org/10.1016/S0378-3774(02)00173-7

[16] Machado, D.C., Maia, C.M., Carvalho, I.D., Fontoura da Silva, N., André, M.C.D.P.B. and Serafini, Á.B. (2006) Microbiological quality of organic vegetables produced in soil treated with different types of manure and mineral fertilizer. Brazil Journal of Microbiology, 37.

[17] Yasmeen, M., Bari, M.L., Inatsu, Y. and Kawamoto, S. (2008) Effect of transient temperature shift-up on the growth of aerobic bacteria, coliform and Listeria monocytogenes on cut cabbage during storage. Food Science Technological Research, 14, 493.

http://dx.doi.org/10.3136/fstr.14.493

[18] Ibrahim, T.A. and Jude-Ojei, B. (2009) Microbiological analysis and effect of selected antibacterial agents on microbial load of fluted pumpkin, cabbage and bitter leaves. The Internet Journal of Microbiology, 7, 2.

[19] Stine, S.W., Song, I., Choi, C.Y. and Gerba, C.P. (2005) Application of microbial risk assessment to the development of standards for enteric pathogens in water used to irrigate fresh produce. Journal of Food Protection, 68, 913-918.

[20] Akbar, M.F., Haq, M.A., Parveen, F., Yasmin, N. and Khan, 
M.F.U. (2010) Comparative management of cabbage aphid (myzus persicae (sulzer) (aphididae: Hemiptera) through bio- and synthetic-insecticides. Pakistan Entomology, 32, 12-17.

[21] Xu, J. and Warriner, K. (2005) Coliphage as an indicator of fecal contamination in hydroponic cucumber (Cucumis sativus L.) greenhouses. Journal of Science Food Agriculture. http://dx.doi.org/10.1002/jsfa.2249

[22] Jensen, A.N., Storm, C., Forslund, A., Baggesen, D.L. and Dalsgaard, A. (2010) Faecal contamination of lettuce heads after manure application. 22nd International ICFMH Symposium Food Micro 2010, 280.

[23] Heinonen-Tanski, H., Sjöblom, A., Fabritius, H. and Karinen, P. (2007) Pure human urine is a good fertiliser for cucumbers. Bioresource Technology, 98, 214-217. http://dx.doi.org/10.1016/j.biortech.2005.11.024

[24] Mukherjee, A., Speh, D., Dyck, E. and Diez-gonzalez, F. (2004) Preharvest evaluation of coliforms, Escherichia coli, Salmonella, and Escherichia coli O157:H7 in organic and conventional produce grown by Minnesota farmers. Journal of Food Protection, 67, 894-900.

[25] Solomon, E.B., Pang, H.J. and Matthews, K.R. (2003) Persistence of Escherichia coli O157:H7 on lettuce plants following spray irrigation with contaminated water. Journal of Food Protection, 66, 2198-2202.

[26] Simoes, M., Pisani, B., Marques. E.G.L., Prandi. M.A.G., Martini, M.H., Chiarini, P.F.T., Antunes, J.L.F. and Nogueira, A.P. (2001) Hygienic-sanitary conditions of vegetables and irrigation water from kitchen gardens in the mu- nicipality of Campias, SP. Brazil Journal of Microbiology, 32, 1-5. http://dx.doi.org/10.1590/S1517-83822001000400015

[27] Valentin-Bon, I., Jecobson, A., Mondey, S.R. and Feng, P.C.H. (2008) Microbiological quality of bagged cut spinach and lettuce mixes. Applications and Environmental Microbiology, 74, 1240-1242. http://dx.doi.org/10.1128/AEM.02258-07

[28] Dogan-Halkman, H.B., Çakýr, I., Keven, F., Worobo, R. W. and Halkman, A.K. (2003) Relationship among fecal coliforms and Escherichia coli in various foods. European Food Research and Technology, 216, 331-334.

[29] Bueschkens, D.H. and Stiles, M.E. (1984) Escherichia coli variants for gas and indole production at elevated incubation temperatures. Applied Environmental Microbiology, 601-605.

[30] Pupo, G.M., Lan, R. and Reeves, P.R. (2000) Multiple independent origins of Shigella clones of Escherichia coli and convergent evolution of many of their characteristics, Proceedings of National Academy Science of USA. http://dx.doi.org/10.1073/pnas.180094797

[31] Stephan, R., Schumacher, S., Corti, S., Krause, G., Danuser, J. and Beutin, L. (2008) Prevalence and characteristics of Shiga toxin-producing Escherichia coli in Swiss raw milk cheeses collected at producer level. Journal of Dairy Science, 91, 2561-2565. http://dx.doi.org/10.3168/jds.2008-1055 